\title{
Endpoints for Pre-Dementia AD Trials: A Report from the EU/US/ CTAD Task Force
}

\author{
B. Vellas ${ }^{1,2,3}$, R. Bateman 4 , K. Blennow ${ }^{5}$, G. Frisoni ${ }^{6,7}$, K. Johnson ${ }^{8}$, R. Katz ${ }^{9}$, J. Langbaum ${ }^{10}$, D. Marson ${ }^{11}$, \\ R. Sperling ${ }^{12}$, A. Wessels ${ }^{13}$, S. Salloway ${ }^{14}$, R. Doody ${ }^{15}$, P. Aisen ${ }^{16}$ and Task Force Members*
}

1. UMR1027 Inserm, F-31073, Toulouse, France; 2. University of Toulouse III, F-31073, France; 3. Gerontopole Toulouse, Toulouse University Hospital, F-31000, Toulouse, France; 4. Washington University School of Medicine, St. Louis, MO, USA; 5. University of Gothenburg, MöIndal Hospital, Sahlgrenska University Hospital, 43180 MöIndal, Sweden; 6. University Hospitals and University of Geneva, Geneva, Switzerland; 7. IRCCS Fatebenefratelli, Brescia, Italy; 8. Massachusetts General Hospital, Harvard Medical School, Boston, MA USA; 9. Division of Neuropharmacological Drug Products, U.S. Food and Drug Administration, USA; 10. Banner Alzheimer's Institute, Phoenix, AZ, USA; 11. The University of Alabama at Birmingham, Birmingham, AL, USA; 12. Brigham and Women's Hospital, Harvard Medical School, Boston, MA, USA; 13. Eli Lilly and Company, Indianapolis, IN, USA; 14. The Warren Alpert Medical School of Brown University, Providence, RI, USA; 15. Baylor College of Medicine, Houston, TX, USA; 16. Department of Neurosciences, University of California, San Diego, San Diego, CA USA

Corresponding Author: Bruno Vellas, UMR1027 Inserm, F-31073, Toulouse, France; University of Toulouse III, F-31073, France; Gerontopole Toulouse, Toulouse University Hospital, F-31000, Toulouse, France, vellas.b@chu-toulouse.fr

* E.U./U.S. CTAD TASK FORCE members: Susan Abushakra (San Mateo), Sandrine Andrieu (Toulouse), Joanne Bell (Cambridge), Gene Bowman (Lausanne), Sasha Bozeat (Utrech), Robert Brashear (San Francisco), Marc Cantillon, Maria Carrillo (Chicago), Jesse Cedarbaum (Cambrdige), Er Chen (San Francisco), Isabelle Clavier (Chilly Mazarin), Caroline Cohen (Chilly Mazarin), Eskild Colding-Jorgensen (Valby), Csilla Csoboth (San Francisco), Jeffrey Cummings (Las Vegas), Rachelle Doody (Houston), Bruno Dubois (Paris), Jane Durga(Vevey), Michael Egan (North Wales), Laura Eggermont (Utrech), Laura Gault (Chicago), Serge Gauthier (Verdun), Bram Goorden (Vevey), Mark Gordon (Ingelheim),Michael Grundman (San Diego), Harald Hampel ((Paris), Paul Hartung (Acton), Roza Hayduk (San Diego), Suzanne Hendrix (USA), Robert Hoerr (Karlsruhe), Michael Keeley (San Francisco), Ara Khachaturian (Potomac), Zaven S. Khachaturian (Potomac), Robert Lasser (Basel), John Lawson (Malvern), Valérie Legrand (Nanterre),Constantine Lyketsos (Baltimore), Richard Meibach (East Hanover), Annette Merdes (Munich), Mark Mintun (Philadelphia), Hans Moebius (Brunnen), Cristina Murat(Marly le Roi), Philip Nichols (Lausanne), Pierre Jean Ousset (Toulouse), Jana Podhorna (Ingelheim), Maria Pueyo (Suresnes), Christopher Randolph (Hamilton), David Raunig (New Hope), Vanessa S. Reddy (Basel), Philippe Robert (Nice), Gary Romano (Titusville), Allen Roses (Chapel Hill), Juha Rouru (Turku), Ivana Rubino (Basel),Michael Ryan (East Hanover), Stephen Salloway (Providence), Philip Scheltens (Amsterdam), Rachel J. Schindler (New York), Achim Schneeberger (Vienna), Lon Schneider (Los Angeles), Jeffrey Sevigny (Cambridge), Klaudius Siegfried (Langen), Eric Siemers (Indianapolis), Joao Siffert (Aliso Viejo), Chang-Heok Soh (Basel), Maria E. Soto-Martin (Toulouse), Johannes Streffer (Beerse), Joyce Suhy (Newark), Jacques Touchon (Montpellier), Gabriel Vargas (Thousand Oaks), Estelle Vester-Blokland(Basel), Michael Weiner (San Francisco), Glen Wunderlich (Ingelheim)

\begin{abstract}
For Alzheimer's disease treatment trials that focus on the pre-dementia stage of disease, outcome measures are needed that will enable assessment of disease progression in patients who are clinically normal. The EU/US CTAD Task Force, an international collaboration of investigators from industry, academia, non-profit foundations, and regulatory agencies, met in Philadelphia, Pennsylvania, USA, on November 19, 2014 to discuss existing and novel outcome assessments that may be useful in pre-dementia trials. Composite measures that assess changes in episodic memory, executive function, global cognition, and global function have recently been developed by a number of groups and appear to be sensitive at this stage. Functional measures that involve real-life complex tasks also appear to capture early subtle changes in pre-dementia subjects and have the advantage of representing clinically meaningful change. Patient reported outcomes and novel CSF and imaging biomarkers have also shown promise. More studies are needed to validate all of these tests in the pre-dementia population. Many of them have been incorporated as exploratory measures in ongoing or planned trials.
\end{abstract}

Key words: Pre-dementia Alzheimer's disease, cognitive outcome assessments, functional outcome assessments, biomarkers.

\section{Introduction}

7 Treatment of Alzheimer's disease (AD) has moved increasingly into the pre-dementia space, as the field has coalesced around the idea that the best chance for slowing or preventing dementia will require intervening before substantial neurodegeneration has taken place (1). This approach reflects accumulating knowledge from prospective cohort studies in healthy elderly individuals, patients with mild cognitive impairment (MCI), and $\mathrm{AD}(2)$; as well as longitudinal studies in carriers of deterministic autosomal dominant mutations (3), which indicate that the pathological processes that underlie $\mathrm{AD}$ begin decades before symptoms become apparent, and that the amount of pathology is advanced already in the MCI stage of the disease.

Designing secondary prevention trials for predementia populations presents many challenges, including how to identify appropriate subjects for such trials and how to assess treatment effectiveness. The EU/ US -CTAD Task Force, an international collaboration of investigators from academia, industry, non-profit foundations and regulatory agencies met in Philadelphia on November 19, 2014 to address some of these challenges, in particular, the need for measures that will enable assessment of disease progression in a normal, or near-normal population that is destined to develop AD 
because of genetic or other risk factors.

Five large prevention trials have recently been launched or are in the planning stages, taking different approaches to the challenge of identifying appropriate study populations at high risk for AD (Table 1). The Dominantly Inherited Alzheimer Network Trials Unit (DIAN-TU, www.DIAN-TU.org, Clinicaltrials.gov identifier NCT01760005) trial (4) and the Alzheimer's Prevention Initiative (API) Autosomal Dominant Alzheimer's Disease (ADAD) trial (Clinicaltrials.gov identifier NCT01998841) (5, 6), include individuals with rare genetic mutations in genes that confer near certainty of developing early onset AD; The API APOE4 trial will enroll people who are at increased genetic risk of developing late onset $\mathrm{AD}$ based on their APOE genotype (6); The TOMMORROW trial is enrolling people with a genetically-based increased risk of AD determined through the use of a pharmacogenetic algorithm based on TOMM40 and APOE genotype and age (7); and the Anti-Amyloid Treatment in Asymptomatic Alzheimer's (A4) Study is enrolling individuals who are known to have significant quantities of amyloid deposition in their brains as identified by positron emission tomography (PET) scans (8).

\begin{tabular}{|c|c|c|}
\hline Name of trial & Enrichment criteria & Treatment \\
\hline DIAN-TU 1 & $\begin{array}{l}\text { Autosomal dominant mutations } \\
\text { in APP, PSEN1, PSEN2 }\end{array}$ & $\begin{array}{l}\text { Gantenerumab } \\
\text { Solanezumab }\end{array}$ \\
\hline API-ADAD ${ }^{2}$ & $\begin{array}{l}\text { Autosomal dominant mutations } \\
\text { in PSEN1 E280A }\end{array}$ & Crenezumab \\
\hline API-APOE $4^{3}$ & $\begin{array}{l}\text { Homozygosity of the ApoE } \varepsilon 4 \\
\text { allele }\end{array}$ & $\begin{array}{l}\text { CAD106 } \\
\text { BACE inhibitor }\end{array}$ \\
\hline TOMMORROW & $\begin{array}{l}\text { Algorithm based on TOMM40 } \\
\text { and APOE genotypes }\end{array}$ & Pioglitazone \\
\hline $\mathrm{A} 4^{4}$ & Positive PET amyloid scan & Solanezumab \\
\hline
\end{tabular}

1- Dominantly Inherited Alzheimer's Network-Trials Unit trial; 2- Alzheimer's Prevention Initiative Autosomal Dominant Alzheimer's Disease trial; 3- Alzheimer's Prevention Initiative APOE4 trial; 4- Anti-Amyloid Treatment in Asymptomatic Alzheimer's Study

Assessing the effects of a treatment in a predementia population is complicated. The U.S. Food and Drug Administration (FDA) recently published a draft guidance outlining their thinking about drug development of early stage AD (9). In this guidance, they note the difficulty of using time-to-dementia as an endpoint in clinical trials since it fails to take into account the gradually progressive nature of the disease. They suggested using continuous outcome measures, such as the Clinical Dementia Rating Sum of Boxes (CDR-SB) scale; yet while such measures may enable efficient trial design, they do not eliminate the need for large trials with long duration. Moreover, while the CDR-SB may represent a useful outcome measure for subjects with $\mathrm{MCI}$, it lacks sensitivity in the pre-clinical stages of the disease (10).

In the revised criteria proposed by the National
Institute on Aging and Alzheimer's Association (NIAAA) (10-12) and an International Working Group (IWG) $(13,14)$, biomarkers were incorporated into the diagnostic framework. These criteria thus operationalized prodromal $\mathrm{AD}$ as $\mathrm{MCI}$ plus biomarkers (e.g., elevated amyloid-ligand retention on PET or low cerebrospinal fluid (CSF) amyloid-beta 1-42 peptide (A $\beta 42)$ and led to the acceptance of prodromal $\mathrm{AD}$ as a target for drug development.

\section{Cognitive/clinical endpoints}

The recommendations for revised diagnostic criteria were based on the Dubois criteria (15) and the hypothetical model proposed by Jack et al $(16,17)$, which suggested that the disease can be defined as a trajectory of biomarker and clinical changes prior to the onset of dementia. Data obtained from the Alzheimer's Disease Neuroimaging Initiative (ADNI), DIAN (3), API (18), and other studies have in general supported the hypothetical model, but have revealed additional complexity. Rather than indicating that the various measures progress sequentially, i.e., amyloid first followed by tau abnormalities, brain structural changes, and finally changes in memory and function, the data suggest that these abnormalities overlap, and may change more in parallel during the evolution of AD. The trajectory prescribed also depends on the sensitivity of each biomarker or test instrument used (19). Even cognitive measures move roughly in parallel with other assessments of disease progression, including biomarkers, suggesting that cognition may function as an appropriate outcome measure for clinical trials (20).

However, measures of cognition currently used are not sensitive in early disease. For example, the Alzheimer's Disease Assessment Scale Cognitive Subscale (ADAS$\mathrm{Cog}$ ) is the most widely used cognitive outcome measure used in clinical trials of AD treatments, yet lacks sensitivity to detect subtle cognitive changes in prodromal disease (21). This has led to multiple efforts to develop a single composite scale optimized for patients with MCI. These composites have been constructed in one of two ways, driven either by neuropsychological theory or analysis of data from observational studies and clinical trials. Theory-driven composites are based on traditional neuropsychological measures known to assess domains sensitive to decline in AD, such as word list, story recall, and executive function; whereas data-drive composites included only those items from the ADAS-Cog, CDR-SB, Mini-Mental State Exam (MMSE), Functional Activities Questionnaire (FAQ), and Instrumental Activities of Daily Living (IADL) questionnaires that demonstrated the most decline over time (22-24). Theory- and data-driven composites had a similar set of domains - episodic memory, executive function, global cognition, and global function included, although there was some variation in the assessment tools 


\begin{tabular}{|c|c|c|c|c|c|}
\hline Composite & ADAS-Cog items & CDR & MMSE & FAQ & Other \\
\hline $\begin{array}{l}\text { ProADAS } \\
\text { (Astra Zeneca) (25) }\end{array}$ & $\begin{array}{l}\text { Word recall } \\
\text { Delayed word } \\
\text { recall } \\
\text { Orientation } \\
\text { Word finding } \\
\text { Number Cancella- } \\
\text { tion }\end{array}$ & & & & \\
\hline $\begin{array}{l}\text { TriAD (Janssen) } \\
(24)\end{array}$ & $\begin{array}{l}\text { Word recall } \\
\text { Delayed word } \\
\text { recall } \\
\text { Orientation }\end{array}$ & 3 cognition boxes & & & \\
\hline $\begin{array}{l}\text { ADCCS (Janssen) } \\
\text { (26) }\end{array}$ & $\begin{array}{l}\text { Word Recall } \\
\text { Delayed word } \\
\text { recall } \\
\text { Orientation } \\
\text { Word recognition }\end{array}$ & All items & & & \\
\hline $\begin{array}{l}\text { ADCOMS (Eisai) } \\
\text { (22) }\end{array}$ & $\begin{array}{l}\text { Delayed word } \\
\text { recall } \\
\text { Orientation } \\
\text { Word recognition } \\
\text { Word finding }\end{array}$ & All items & $\begin{array}{l}\text { Orientation } \\
\text { Constructional } \\
\text { praxis }\end{array}$ & & \\
\hline $\begin{array}{l}\text { ProADAS + FAQ/ } \\
\text { iADL (25) }\end{array}$ & $\begin{array}{l}\text { Word recall } \\
\text { Delayed word } \\
\text { recall } \\
\text { Orientation } \\
\text { Word finding } \\
\text { Number Cancella- } \\
\text { tion }\end{array}$ & & & All items & $\begin{array}{l}\text { ADCS-ADL: iADL } \\
\text { items }\end{array}$ \\
\hline $\begin{array}{l}\text { ADAS-Cog + FAQ/ } \\
\text { iADL }\end{array}$ & All items & & & All items & $\begin{array}{l}\text { ADCS-ADL: iADL } \\
\text { items }\end{array}$ \\
\hline Pfizer (23) & $\begin{array}{l}\text { Word recall } \\
\text { Delayed word } \\
\text { recall } \\
\text { Orientation }\end{array}$ & All items & & All items & \\
\hline
\end{tabular}

used (Table 2).

The performance of these composites was compared using data sets from ADNI, the Baltimore Longitudinal Study of Aging (BLSA), and phase 3 placebo and treatment arm data from mild $\mathrm{AD}$ patients enrolled in the solanezumab trial. This analysis concluded that the highest signal to noise ratios (SNRs) in observational/ placebo data were observed for composites that include both cognition and function, regardless of whether the composites were theory or data driven. For the solanezumab treatment data, the highest SNRs were observed for pure cognitive measures. Therefore, composites that show high SNRs in placebo groups did not necessarily show high SNRs for treatment differences.

Composites have also been built for use in the previously mentioned prevention trials (Table 3 ). The Alzheimer's Disease Cooperative Study's Preclinical Alzheimer's Cognitive Composite (ADCS-PACC), for example, is the primary outcome measure for the A4 trial (27); the API used an empirically-driven approach to create two cognitive composites to be used in as the primary endpoints in their trials $(28,29)$; and the DIANTU is also developing their own cognitive composite, using three complementary approaches to select items: 1) a data-driven approach to derive the optimal combination of items; 2) a theoretical approach, and 3) an exploratory factor analysis approach. All three approaches indicated that measures of delayed recall memory were sensitive to pre-symptomatic decline.

Each of these composites was developed and tested in the specific population targeted in the associated trial. For example, the API composites were developed using data from multiple cohorts with the goal of identifying the combinations most sensitive to detecting and tracking preclinical cognitive decline in populations at risk for clinical progression to ADAD or late-onset AD. Data from the Antioquia PSEN1 E280A cohort were used to derive the API ADAD composite, corresponding to the population enrolled in the API-ADAD trial (28). Data from three longitudinal cohorts from the Rush 
Table 3. Cognitive and Clinical Assessments in Preclinical AD Trials: Primary endpoint

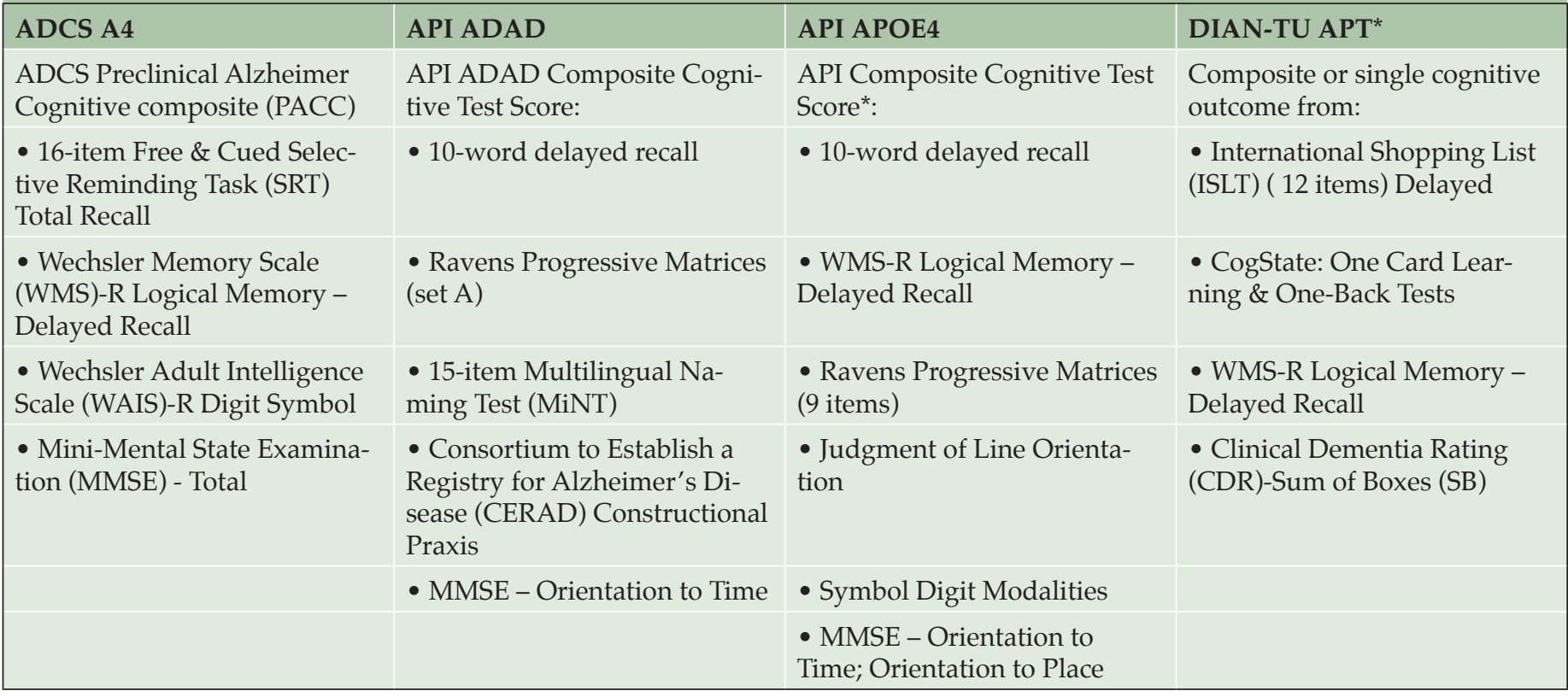

Adapted from tables provided by the Collaboration for Alzheimer's Prevention; * finalization pending

Alzheimer's Disease Center's Religious Orders Study, Memory and Aging Project, and Minority Aging Research Study were used to derive a composite sensitive to detecting and tracking cognitive decline in individuals who progress to the clinical stages of late onset AD (29). This composite is currently being refined for use in the API APOE4 Trial.

The DIAN-TU composite was developed using data from the DIAN Observational Study (30), while the ADCS-PACC composite was developed using observational data from ADNI and the Australian Imaging, Biomarkers, and Lifestyle Flagship Study of Ageing (AIBL) (27). Importantly, API, DIAN-TU, and A4 have come together under the umbrella of the Collaboration for Alzheimer's Prevention (CAP) to ensure that their composites are aligned and comparable.

Another simple-to-administer tool being developed to assess cognition in early stages of the disease is the ADCS Cognitive Function Index (31), which incorporates both self and partner ratings and is also being developed as an IPAD version. Interestingly this index indicates that self and partner ratings of cognitive impairment change at different rates. In very early stages, patients rate their cognition worse than do their study partners, but as the disease progresses, the partner ratings begin to catch up.

Task force participants agreed that more work needs to be done to increase our understanding of the components of cognition that begin to fail in the earliest stages of the disease, as well as their relationship to the underlying disease, clinically meaningful change and response to drug treatment.

\section{Functional endpoints}

The hypothetical model proposed by Jack et al. in 2010 suggested that functional impairment is a late manifestation of AD (17). However, recent studies suggest that impairments in instrumental activities of daily living (IADLs) occur even in cognitively normal individuals who later progress to $\mathrm{MCI}$ or $\operatorname{AD}(32,33)$. Mirroring previously-mentioned studies showing subtle cognitive impairment in preclinical AD, these studies of IADL decline suggest that functional impairment also occurs in preclinical AD and may be inextricably intertwined with cognitive impairment. The challenge is to identify sensitive measures capable of detecting very small functional signals in the preclinical space. Such measures would likely need to incorporate cognitively complex skills with finely grained interval scaled direct performance variables, as well as time-to-completion variables (34).

Recent studies have deepened understanding of the relationship of cognition and function. Using clinical trial data from solanezumab trials, Liu-Seifert et al. showed through path analysis approaches that in mild $\mathrm{AD}$, cognitive change leads to functional change and not-vice-versa (35). The correlations between cognition and function also increase over time as functional decline become more apparent. These data suggest that cognitive measures predict functional outcomes.

Composites that include both cognitive and functional elements are also being investigated for their sensitivity in early $\mathrm{AD}$. The AD Composite (ADCOMS) is being used in a trial of E2609, a beta-site amyloid precursor protein-cleaving enzyme (BACE) inhibitor (NCT02322021). The trial includes patients with mild AD 
dementia and prodromal AD. ADCOMS is an analytic approach that includes questions from the ADAS-Cog, CDR and Mini-Mental State Examination.

Financial capacity represents a complex set of functional skills that are highly vulnerable to AD cognitive decline (36). For example, studies using the Financial Capacity Instrument have shown that financial skills decline in MCI and mild-to-moderate AD (37-39). Using structural MRI, this decline has been linked to volume loss in regions of the default mode network $(40,41)$. More recently, a short form version of the instrument, the FCI-SF, has been developed to investigate functional impairment in earlier phases of AD (42). The FCI-SF includes both performance and time to completion variables related to constructs such as financial conceptual knowledge and use of a checkbook and register. In a study comparing amyloidpositive and amyloid-negative groups of community based, cognitively normal older subjects (determined by PET scanning and cognitive assessments), the measure detected functional changes on several FCI-SF variables in the amyloid positive group. The findings suggested that functional change may occur in $\mathrm{AD}$ much earlier than previously thought, and that in addition to cognitive measures, direct performance measures of complex function might also serve as outcomes in preclinical AD (42). In order to make functional measures like the FCI-SF usable across countries and cultures that have different financial systems and mores, it may be necessary to distill test items into core cognitive abilities that cross financial and cultural lines, such as numeracy and visual scanning of complex numerical information.

Another performance-based ADL instrument was described that incorporates three real-life tasks: the first requires subjects to refill a prescription over the telephone, the second to select a new primary care physician over the telephone, and the third to make a bank transfer. For the automated phone menu tasks, both time and errors were significantly different between subjects who were clinically normal compared to those with MCI, and these findings correlated with inferior temporal cortical thinning (43). Another approach, taken by the Critical Path Institute (C-Path), involves developing a patient-reported outcome instrument to assess complex ADLs and interpersonal functioning for use in MCI trials.

Incorporating functional measures into clinical trials poses several concerns. First, since functional change appears to be non-linear, increasing around the late-MCI stage, delayed start designs could be challenging. Second, although functional measures most directly correspond to clinical meaningfulness, they are not specific for AD. However, from a regulatory point of view, if a drug was able to show a benefit in both cognitive and functional outcomes in patients on the AD spectrum, these findings might be sufficient for approval.

\section{Imaging and biomarker endpoints}

AD biomarkers may be useful in clinical trials not only for enrichment purposes but also to provide objective evidence of target engagement and disease-modifying effects (44). Indeed, the recent FDA draft guidance on developing drugs for early stage disease (9) suggested that the agency might consider the possibility "that a claim of disease modification could be supported by evidence of a meaningful effect on a biomarker in combination with a clinical benefit." Similarly, the European Medicines Agency (EMA) has suggested that biomarkers could provide supportive evidence for disease modification (45). However, both regulatory agencies stress that to be used as outcome measures in drug trials, data are needed that link the biomarker findings to downstream effects of drugs and clinical outcomes. The EU/US Task Force discussed progress in developing three types of biomarkers that have shown promise as outcome measures in clinical trials: Cerebrospinal fluid (CSF) biochemical markers, structural magnetic resonance imaging (MRI) markers, and tau imaging with positron emission tomography (tau PET).

Biomarker development has been fueled in large part by ADNI, which set out as one of its primary objectives the validation and standardization of biomarkers. Among CSF biomarkers, levels of A $\beta 42$, total tau (t-tau), and phosphorylated tau ( $\mathrm{p}$-tau) have been the most widely studied. While the combination of low $\mathrm{A} \beta 42$, high $\mathrm{t}$-tau, and high $\mathrm{p}$-tau represents a sensitive and specific signature for prodromal AD (46), the use of these measures individually or in combination as endpoints in clinical trials has not been demonstrated. For example, in the recently completed solanezumab pivotal trials in mild-to-moderate $\mathrm{AD}$, treatment resulted in an increase in total CSF A $\beta 42$ as well as other CSF changes suggestive of target engagement; these changes were not associated with significant improvement in the primary cognitive endpoint, but were associated with beneficial trends in some cognitive measures (47). In addition, the phase 2 bapineuzumab trial and both the phase 3 trials all showed a modest lowering of CSF p-tau by approximately $10 \%$ with treatment, suggestive of downstream effects on the neurodegenerative process that was not associated with any cognitive improvement $(48,49)$. There are several possible reasons for this finding, including the likelihood that subjects were too far advanced along the disease continuum to benefit from the treatment or that there was too little target engagement. Future studies will explore whether CSF biomarkers may be useful as outcome measures in prodromal trials.

The use of CSF biomarkers in clinical trials will require standardized protocols, harmonization across different assay platforms, and the establishment of universal cutoff values to identify individuals with disease pathology. The Alzheimer's Association's Global 
Biomarkers Standardization Consortium (GBSC), in collaboration with the Institute for Reference Materials and Methods (IRMM) and the International Federation of Clinical Chemistry and Laboratory Medicine (IFCC), has made substantial progress in this regard (50). They have developed a mass spectroscopy-based reference measurement procedure (RMP) for CSF A $\beta 42$, which has demonstrated excellent agreement between two labs, and long-term stability tests and value assignment of a certified reference material (CRM) is ongoing (51, 52). They have also demonstrated that fully automated instruments may solve the problem of betweenlab variability. It is promising that in the Alzheimer's Association Quality control program, which serves to monitor between-lab and longitudinal variability for the CSF biomarkers (53), the variability dropped from the usual $15-20 \%$ to a few percent the first round the new type of automated lab analyzers were evaluated.

It is likely that novel CSF biomarkers will be needed if they are to be used as outcome measures. Synaptic degeneration is a central and early phenomenon during the evolution of $\mathrm{AD}$, and the degree of synaptic degeneration shows a robust correlation with severity of cognitive symptoms $(54,55)$. Measurement of synaptic proteins in CSF may thus correlate with cognition and serve as biomarkers for AD. A recent study showed that CSF levels of the dendritic protein neurogranin are increased in $\mathrm{AD}$ and correlate with future cognitive decline in amyloid positive and prodromal AD cases (56). In a study of MCI subjects enrolled in ADNI, patients with high levels of CSF neurogranin were also found to have a more rapid decline in MMSE scores (unpublished). Thus, synaptic proteins in CSF might serve to monitor effects on synaptic integrity in trials on drug candidates targeting $A \beta$ or tau pathology or investigating neuroprotective mechanisms.

Structural MRI has also been proposed as a useful endpoint in AD clinical trials. Brain atrophy is seen in both normal and pathological aging and in healthy older adults brain atrophy has been shown to correlate with pathological CSF profiles (57). In MCI patients who progress to $\mathrm{AD}$, atrophy rates map to brain areas where neurodegeneration is taking place (58). As with CSF biomarkers, for structural atrophy to be used as an endpoint, the measure must be linked to clinical outcome.

For hippocampal atrophy to be used either diagnostically or in clinical trials, standardization and harmonization are again essential (59). A harmonized protocol for manual hippocampal segmentation was recently developed and validated by a collaborative project of The European Alzheimer's Disease Consortium (EADC) and ADNI, with support from the Alzheimer's Association (60). This group tested the variance due to different tracers, scanners, post-processing pipeline, and manual vs. automated segmentation. They concluded that the harmonized protocol has high measurement stability and good reproducibility across tracers and scanners.

A newer imaging method that has generated much excitement across the field uses PET scanning to assess tau deposition in the brain. Several different radiotracers are in development. One of the most promising is a fluorine-18 labeled compound called T807 (61). This compound binds selectively to paired helical filaments of tau. Tau binding shows a stronger relationship to impairment compared to amyloid imaging, and anatomically, the pattern of binding is consistent with Braak stages of tauopathy.

Many issues need to be explored and optimized to advance the use of tau imaging for diagnosis and clinical research. These issues include improving the resolution of images, assessing off-target binding, and better understanding the regional distribution of tau and its relationship to CSF findings. The current hypothesis is that neocortical tau represents incident impairment due to $\mathrm{AD}$, with large effect sizes comparing normal vs impaired. If it tracks closely with clinical impairment, is proximal to clinical change, and represents a downstream consequence of some other toxicity, it may be useful as an endpoint for therapeutic trails of an anti-amyloid treatment. Longitudinal data from studies currently underway should be available in 2015; and importantly, thanks to grants from the Accelerated Medicine Partnership (AMP) and the Alzheimer's Association, tau imaging will be included in the DIAN-TU, API, and A4 trials.

\section{Paving the way for combination treatments for early Alzheimer's disease}

Developing treatments to slow the progression of AD poses significant challenges. Among these are determining the optimal stage of treatment and maximally engaging one or more treatment targets for this complex neurodegenerative disorder. The most recent large scale phase 3 treatment trials testing anti-amyloid therapies have yielded negative or at best equivocal results, in part due to insufficient target engagement and relatively late disease stage. There is a growing consensus among $\mathrm{AD}$ experts that $\mathrm{AD}$ is best treated in early stages before substantial neurodegeneration and disability have occurred. The goal of intervention is to have a major impact on slowing the disease course and preserving quality of life. Meeting this goal, as with other complex chronic medical conditions such as heart disease, cancer, and HIV, will likely best be accomplished by combining 2, 3, 4, or more medications (62). Now is the time to tackle the hurdles and begin paving the way for combination therapies for AD. Planning needs to begin in earnest to identify rational combinations, trial designs, and target populations, and solving the safety, regulatory, and intellectual property issues likely to arise. The US-EU Task Force is in a good 
position to take a lead role in this effort.

As Dr. Rusty Katz underlined during the Task Force meeting, one way to approach combinations is with adaptive clinical trial designs. The agency in 2010 issued draft guidances on adaptive trials (63) and codevelopment (64). Adaptive designs are complex and must be well planned. However, from a clinical perspective they are more efficient designs. This guidance suggests that almost all aspects of a trial can be adapted: from eligibility criteria, randomization, treatment regimens and arms, sample size, to even some endpoints. The main concern with adaptive designs is inflation of type-one errors; the guidance proposes statistical approaches and trial modifications to address this concern.

\section{Conclusion}

EU-US Task Force members expressed optimism about the use of cognitive markers and composite approaches as endpoints in pre-dementia clinical trials. Longitudinal studies suggest that changes on cognitive measures, even while still within the normal range, may herald later development of dementia. Since individuals in the pre-dementia stage are considered clinically "normal," the use of cognitive markers seems counterintuitive, yet it has the advantages of face validity, low cost, ease of use, and applicability across a range of trial sites. Closely intertwined with cognitive markers are functional measures, particularly performance measures that involve real-life, cognitively complex tasks.

Recently launched prevention trials should provide substantial amounts of data that will help determine whether such cognitive and functional measures have the sensitivity and specificity required for clinical trials. These studies will also go a long way towards demonstrating the usefulness of CSF and imaging biomarkers as potential endpoints in pre-dementia trials. Meanwhile, it will be important to continue exploration and discovery of new biomarkers that correlate with memory loss and cognitive function.

Conflict of interest: Authors have no conflicts of interest with this paper. A Wessels is employed by Eli Lilly and Company. The Task Force was partially funded by registration fees from industrial participants. These corporations placed no restrictions on this work.

Acknowledgement: The authors thank Lisa J. Bain for assistance in the preparation of this manuscript.

\section{References}

1. Sperling R, Mormino E, Johnson K. The Evolution of Preclinical Alzheimer's Disease: Implications for Prevention Trials. Neuron. 2014;84(3):608-22.

2. Villemagne VL, Burnham S, Bourgeat P, Brown B, Ellis KA, Salvado O, et al. Amyloid beta deposition, neurodegeneration, and cognitive decline in sporadic Alzheimer's disease: a prospective cohort study. Lancet Neurol 2013;12(4):357-67.

3. Bateman RJ, Xiong C, Benzinger TLS, Fagan AM, Goate A, Fox NC, et al. Clinical, cognitive, and biomarker changes in the Dominantly Inherited Alzheimer Network. N Engl J Med. 2012;367(9):795-804.

4. Mills SM, Mallmann J, Santacruz AM, Fuqua A, Carril M, Aisen PS, et al.
Preclinical trials in autosomal dominant AD: implementation of the DIANTU trial. Rev Neurol (Paris). 2013;169(10):737-43.

5. Bateman RJ, Aisen PS, De Strooper B, Fox NC, Lemere CA, Ringman JM, et al. Autosomal-dominant Alzheimer's disease: a review and proposal for the prevention of Alzheimer's disease. Alzheimers Res Ther. 2011;3(1):1.

6. Reiman EM, Langbaum JB, Fleisher AS, Caselli RJ, Chen K, Ayutyanont N, et al. Alzheimer's Prevention Initiative: a plan to accelerate the evaluation of presymptomatic treatments. J Alzheimers Dis. 2011;26 Suppl 3:321-9.

7. Roses AD, Welsh-Bohmer KA, Burns KL, Chiang C, Crenshaw DG, Lutz MW, et al. A pharmacogenetic-supported clinical trial to delay onset of mild cognitive impairment (MCI) due to Alzheimer's disease. Poster \#34249. Alzheimer's Association International Conference. Vancouver, Canada; 2012.

8. Carrillo MC, Brashear HR, Logovinsky V, Ryan JM, Feldman HH, Siemers ER, et al. Can we prevent Alzheimer's disease? Secondary «prevention» trials in Alzheimer's disease. Alzheimers Dement. 2013;9(2):123-31 e1.

9. Food and Drug Administration. Draft Guidance for Industry. Alzheimer's disease: Developing drugs for the treatment of early stage disease. Accessed 2-24-2013 at http:/ / www.fda.gov/downloads/Drugs/ GuidanceComplianceRegulatoryInformation/Guidances / UCM338287.pdf; 2013.

10. Sperling RA, Aisen PS, Beckett LA, Bennett DA, Craft S, Fagan AM, et al. Toward defining the preclinical stages of Alzheimer's disease: Recommendations from the National Institute on Aging and the Alzheimer's Association workgroup. Alzheimers Dement. 2011;7(3):280-92.

11. Albert MS, Dekosky ST, Dickson D, Dubois B, Feldman HH, Fox NC, et al. The diagnosis of mild cognitive impairment due to Alzheimer's disease: Recommendations from the National Institute on Aging-Alzheimer's Association workgroups on diagnostic guidelines for Alzheimer's disease. Alzheimers Dement. 2011;7(3):270-9.

12. McKhann GM, Knopman DS, Chertkow H, Hyman BT, Jack CR, Jr., Kawas $\mathrm{CH}$, et al. The diagnosis of dementia due to Alzheimer's disease: Recommendations from the National Institute on Aging and the Alzheimer's Association workgroup. Alzheimers Dement. 2011;7(3):263-9.

13. Dubois B, Feldman HH, Jacova C, Cummings JL, Dekosky ST, BarbergerGateau P, et al. Revising the definition of Alzheimer's disease: a new lexicon. Lancet Neurol. 2010;9(11):1118-27.

14. Dubois B, Feldman HH, Jacova C, Hampel H, Molinuevo JL, Blennow K, et al. Advancing research diagnostic criteria for Alzheimer's disease: the IWG-2 criteria. Lancet Neurol. 2014;13(6):614-29.

15. Dubois B, Feldman HH, Jacova C, Dekosky ST, Barberger-Gateau P, Cummings J, et al. Research criteria for the diagnosis of Alzheimer's disease: revising the NINCDS-ADRDA criteria. Lancet Neurol. 2007;6(8):734-46.

16. Jack CR, Jr., Knopman DS, Jagust WJ, Petersen RC, Weiner MW, Aisen PS, et al. Tracking pathophysiological processes in Alzheimer's disease: an updated hypothetical model of dynamic biomarkers. Lancet Neurol. 2013;12(2):207-16

17. Jack CR, Jr., Knopman DS, Jagust WJ, Shaw LM, Aisen PS, Weiner MW, et al. Hypothetical model of dynamic biomarkers of the Alzheimer's pathological cascade. Lancet Neurol. 2010;9(1):119-28.

18. Fleisher A, Chen K, Quiroz Y, et al. Associations between biomarkers and age in the presenilin 1 E280A autosomal dominant Alzheimer's disease kindred a cross-sectional study JAMA Neurology. 2015;in press

19. Braak H, Zetterberg H, Del Tredici K, Blennow K. Intraneuronal tau aggregation precedes diffuse plaque deposition, but amyloid-beta changes occur before increases of tau in cerebrospinal fluid. Acta Neuropathol. 2013.

20. Aisen PS. Cognitive/clinical endpoints for pre-dementia AD trials J Prev Alz Dis. 2015;in press.

21. Posner HB, Cano S, Carrillo MC, Selnes O, Stern Y, Thomas RG, et al Establishing the psychometric underpinning of cognition measures for clinical trials of Alzheimer's disease and its precursors: a new approach. Alzheimers Dement. 2013;9(1 Suppl):S56-60.

22. Hendrix S, Logovinsky V, Perdomo C, Wang J, Satlin A. A new tool for optimizing responsiveness to decline in early AD - abstract OC12. J of Nutr Health Aging 2012;16(9):805.

23. Huang Y, Ito K, Billing CB, Jr., Anziano RJ, for the Alzheimer's Disease Neuroimaging I. Development of a straightforward and sensitive scale for MCI and early AD clinical trials. Alzheimers Dement. 2014

24. Raghavan N, Samtani MN, Farnum M, Yang E, Novak G, Grundman M, et al. The ADAS-Cog revisited: novel composite scales based on ADAS-Cog to improve efficiency in MCI and early AD trials. Alzheimers Dement. 2013;9(1 Suppl):S21-31.

25. Hannesdottir K, Ashwood T, Olsson T, Sjogren N, Jaeger J, Berger A-K, et al Psychometric features of the ADAS-Cog: Identifying a potenetial cognition endpoint for prodromal Alzheimer's disease. Alzheimer Dement. 2013;9(4 Supplement):P461.

26. Snyder PJ, Kahle-Wrobleski K, Brannan S, Miller DS, Schindler RJ, DeSanti S, et al. Assessing cognition and function in Alzheimer's disease clinical trials: do we have the right tools? Alzheimers Dement. 2014;10(6):853-60.

27. Donohue MC, Sperling RA, Salmon DP, Rentz DM, Raman R, Thomas RG, et al. The preclinical Alzheimer cognitive composite: measuring amyloidrelated decline. JAMA Neurol. 2014;71(8):961-70.

28. Ayutyanont N, Langbaum JB, Hendrix SB, Chen K, Fleisher AS, Friesenhahn $\mathrm{M}$, et al. The Alzheimer's Prevention Initiative composite cognitive test score: 
sample size estimates for the evaluation of preclinical Alzheimer's disease treatments in presenilin 1 E280A mutation carriers. J Clin Psychiatry. 2014;in press.

29. Langbaum JB, Hendrix SB, Ayutyanont N, Chen K, Fleisher AS, Shah RC, et al. An empirically derived composite cognitive endpoint with improved power to track and evaluate treatmetns for preclinical Alzheimer's disease. Alzheimer Dement. 2014;10(6):666-74.

30. Moulder KL, Snider BJ, Mills SL, Buckles VD, Santacruz AM, Bateman RJ, et al. Dominantly Inherited Alzheimer Network: facilitating research and clinical trials. Alzheimers Res Ther. 2013;5(5):48.

31. Amariglio RE, Donohue MC, Marshall GA, Rentz DM, Salmon DP, Ferris SH, et al. Tracking early decline in cognitive functionin older individuals at risk for Alzheimer disease dementia: The Alzheimer's Disease Cooperative Study Cognitive Function Instrument. JAMA Neurol. 2015;in press.

32. Farias ST, Chou E, Harvey DJ, Mungas D, Reed B, DeCarli C, et al. Longitudinal trajectories of everyday function by diagnostic status. Psychol Aging. 2013;28(4):1070-5.

33. Marshall GA, Amariglio RE, Sperling RA, Rentz DM. Activities of daily living: where do they fit in the diagnosis of Alzheimer's disease? Neurodegener Dis Manag. 2012;2(5):483-91.

34. Marson D. Investigating functional impairment in preclinical Alzheimer's disease: Potential measure characteristics and methodology. J Prev Alz Dis. 2015; in press.

35. Liu-Seifert H, Siemers E, Sundell K, Price K, Han B, Selzler K, et al. Cognitive and functional decline and their relationship in patients with mild Alzheimer's dementia. J Alzheimers Dis. 2015;43(3):949-55.

36. Marson DC, Sawrie SM, Snyder S, McInturff B, Stalvey T, Boothe A, et al. Assessing financial capacity in patients with Alzheimer disease: A conceptual model and prototype instrument. Arch Neurol. 2000;57(6):877-84.

37. Sherod MG, Griffith HR, Copeland J, Belue K, Krzywanski S, Zamrini EY, et al. Neurocognitive predictors of financial capacity across the dementia spectrum: Normal aging, mild cognitive impairment, and Alzheimer's disease. J Int Neuropsychol Soc. 2009;15(2):258-67.

38. Griffith HR, Belue K, Sicola A, Krzywanski S, Zamrini E, Harrell L, et al. Impaired financial abilities in mild cognitive impairment: a direct assessment approach. Neurology. 2003;60(3):449-57.

39. Triebel KL, Martin R, Griffith HR, Marceaux J, Okonkwo OC, Harrell L, et al. Declining financial capacity in mild cognitive impairment: A 1-year longitudinal study. Neurology. 2009;73(12):928-34.

40. Griffith HR, Stewart CC, Stoeckel LE, Okonkwo OC, den Hollander JA, Martin RC, et al. Magnetic resonance imaging volume of the angular gyri predicts financial skill deficits in people with amnestic mild cognitive impairment. J Am Geriatr Soc. 2010;58(2):265-74.

41. Stoeckel LE, Stewart CC, Griffith HR, Triebel K, Okonkwo OC, den Hollander JA, et al. MRI volume of the medial frontal cortex predicts financial capacity in patients with mild Alzheimer's disease. Brain Imaging Behav. 2013;7(3):282-92.

42. Marson DC, Triebel KL, Gerstenecker A, Martin RC, Edwards K, Pankratz VS, et al. Detecting declining functional skills in preclinical Alzheimer's disease: the Financial Capacity Instrument-Short Form. International Society for CNS Clinical Trials and Methodology (ISCTM). Boston, MA; 2014.

43. Marshall G, Dekhtyar M, Bruno J, Roy K, Masters C, Jethwani K, et al. A new performance-based activities of daily living instrument for early Alzheimer's disease. AAIC. Cophenhagen, Denmark: Alzheimers Dement; 2014:P365.

44. Blennow K. Biomarkers in Alzheimer's disease drug development. Nat Med. 2010;16(11):1218-22

45. European Medicines Agency Committee for Medicinal Products for Human Use (CHMP). Guideline on medicinal products for the treatment of Alzheimer's disease and other dementias. 2008.

46. Blennow K, Dubois B, Fagan AM, Lewczuk P, de Leon MJ, Hampel H. Clinical utility of cerebrospinal fluid biomarkers in the diagnosis of early Alzheimer's disease. Alzheimers Dement. 2014.
47. Doody RS, Thomas RG, Farlow M, Iwatsubo T, Vellas B, Joffe S, et al. Phase 3 trials of solanezumab for mild-to-moderate Alzheimer's disease. N Engl J Med. 2014;370(4):311-21.

48. Blennow K, Zetterberg H, Rinne JO, Salloway S, Wei J, Black R, et al. Effect of immunotherapy with bapineuzumab on cerebrospinal fluid biomarker levels in patients with mild to moderate Alzheimer disease. Arch Neurol. 2012;69(8):1002-10.

49. Salloway S, Sperling R, Fox NC, Blennow K, Klunk W, Raskind M, et al. Two phase 3 trials of bapineuzumab in mild-to-moderate Alzheimer's disease. N Engl J Med. 2014;370(4):322-33.

50. Carrillo MC, Blennow K, Soares H, Lewczuk P, Mattsson N, Oberoi P, et al. Global standardization measurement of cerebral spinal fluid for Alzheimer's disease: an update from the Alzheimer's Association Global Biomarkers Consortium. Alzheimers Dement. 2013;9(2):137-40.

51. Korecka M, Waligorska T, Figurski M, Toledo JB, Arnold SE, Grossman M, et al. Qualification of a surrogate matrix-based absolute quantification method for amyloid-beta(4)(2) in human cerebrospinal fluid using 2D UPLC-tandem mass spectrometry. J Alzheimers Dis. 2014;41(2):441-51.

52. Leinenbach A, Pannee J, Dulffer T, Huber A, Bittner T, Andreasson U, et al. Mass spectrometry-based candidate reference measurement procedure for quantification of amyloid-beta in cerebrospinal fluid. Clin Chem. 2014;60(7):987-94.

53. Mattsson N, Andreasson U, Persson S, Arai H, Batish SD, Bernardini S, et al. The Alzheimer's Association external quality control program for cerebrospinal fluid biomarkers. Alzheimers Dement. 2011;7(4):386-95 e6.

54. Davidsson P, Blennow K. Neurochemical dissection of synaptic pathology in Alzheimer's disease. Int Psychogeriatr. 1998;10(1):11-23.

55. Masliah E, Hansen L, Albright T, Mallory M, Terry RD. Immunoelectron microscopic study of synaptic pathology in Alzheimer's disease. Acta Neuropathol. 1991;81(4):428-33.

56. Kvartsberg H, Duits FH, Ingelsson M, Andreasen N, Ohrfelt A, Andersson K, et al. Cerebrospinal fluid levels of the synaptic protein neurogranin correlates with cognitive decline in prodromal Alzheimer's disease. Alzheimers Dement. 2014.

57. Schott JM, Bartlett JW, Fox NC, Barnes J, Alzheimer's Disease Neuroimaging Initiative I. Increased brain atrophy rates in cognitively normal older adults with low cerebrospinal fluid Abeta1-42. Ann Neurol. 2010;68(6):825-34.

58. Whitwell JL, Przybelski SA, Weigand SD, Knopman DS, Boeve BF, Petersen $\mathrm{RC}$, et al. 3D maps from multiple MRI illustrate changing atrophy patterns as subjects progress from mild cognitive impairment to Alzheimer's disease. Brain. 2007;130(Pt 7):1777-86.

59. Frisoni GB, Fox NC, Jack CR, Jr., Scheltens P, Thompson PM. The clinical use of structural MRI in Alzheimer disease. Nat Rev Neurol. 2010;6(2):67-77.

60. Frisoni GB, Jack CR, Bocchetta M, Bauer C, Frederiksen KS, Liu Y, et al. The EADC-ADNI Harmonized Protocol for manual hippocampal segmentation on magnetic resonance: Evidence of validity. Alzheimers Dement. 2014.

61. Shoup TM, Yokell DL, Rice PA, Jackson RN, Livni E, Johnson KA, et al. A concise radiosynthesis of the tau radiopharmaceutical, [(18) F]T807. J Labelled Comp Radiopharm. 2013;56(14):736-40.

62. Stephenson D, Perry D, Bens C, Bain LJ, Berry DA, Krams M, et al. Charting a path toward combination therapy for Alzheimer's disease. Expert Rev Neurother. 2015;15(1):107-13.

63. Food and Drug Administration. Guidance for industry: Adaptive design clinical trials for drugs and biologics. In: Center for Drug Evaluation and Research CfBEaR, ed; 2010.

64. Food and Drug Administration. Guidance for industry: Codevelopment of two or more unmarketed investigational drugs for use in combination. Accessed online 4/13/14 at www.fda.gov/downloads/Drugs/ GuidanceComplianceRegulatoryInformation/Guidances / UCM236669.pdf; 2010. 